\title{
Effects of agmatine on chlorpromazine-induced neuronal injury in rat
}

\author{
Bratislav Dejanovic ${ }^{1}$, Vesna Vukovic-Dejanovic ${ }^{2}$, Milica Ninkovic ${ }^{3}$, Irena Lavrnja ${ }^{4}$, \\ Ivana Stojanovic ${ }^{5}$, Milos Pavlovic ${ }^{6}$, Vesna Begovic ${ }^{7}$, Dusko Mirkovic ${ }^{8}$, Ivana Stevanovic ${ }^{3}$ \\ ${ }^{1}$ University of Defence, Military Medical Academy, Faculty of Medicine MMA, \\ Institute of Medical Biochemistry, Belgrade, Serbia \\ ${ }^{2}$ Insitute for Rehabilitation, Belgrade, Serbia \\ ${ }^{3}$ University of Defence, Military Medical Academy, Faculty of Medicine MMA, \\ Institute for Medical Research, Belgrade, Serbia \\ ${ }^{4}$ Institute for Biological Research "Sinisa Stankovic", Belgrade, Serbia \\ ${ }^{5}$ University of Nis, Faculty of Medicine, Institute for Biochemistry, Nis, Serbia \\ ${ }^{6}$ Faculty of Veterinary Medicine, Department of Obstetrics, Belgrade, Serbia \\ ${ }^{7}$ University of Defence, Military Medical Academy, Faculty of Medicine MMA, Clinic for Infectious and \\ Tropical Disease, Belgrade, Serbia \\ ${ }^{8}$ Faculty of Pharmacy, Department of Medicinal Biochemistry, Institute for Medical Biochemistry Clinical \\ Centre of Serbia, Belgrade, Serbia
}

Received February 24, 2017

Accepted May 15, 2018

\begin{abstract}
This study was aimed to study the potentially beneficial effects of agmatine on oxidative/ nitrosative stress development in the brain of Wistar rats during subacute chlorpromazine treatment. The animals were divided into control ( $0.9 \%$ saline $)$, chlorpromazine $(38.7 \mathrm{mg} / \mathrm{kg}$ b.w.), chlorpromazine+agmatine (agmatine $75 \mathrm{mg} / \mathrm{kg} \mathrm{b.w.} \mathrm{immediately} \mathrm{after} \mathrm{chlorpromazine,} 38.7 \mathrm{mg}$ / $\mathrm{kg}$ b.w. i.p.) and agmatine ( $75 \mathrm{mg} / \mathrm{kg}$ b.w.) groups. All the tested substances were administered intraperitoneally for 15 consecutive days and the rats were sacrificed by decapitation on day 15 . Subacute administration of chlorpromazine resulted in increased lipid peroxidation, nitric oxide concentration and superoxide anion production, while completely damaging the antioxidant defence system in the cerebral cortex, striatum, and hippocampus. However, the combined treatment with chlorpromazine and agmatine significantly attenuated the oxidative/nitrosative stress indices and restored the antioxidant capacity to the control values in all of the examined brain regions. Western blot analysis supported biochemical findings in all groups, but the most notable changes were found in the hippocampus. Our results suggest potentially beneficial effects of agmatine, which may be useful in the modified antioxidant approach in chlorpromazinetherapy.
\end{abstract}

\section{Antioxidant defence, brain, oxidative stress}

Antipsychotics are used extensively in the treatment of schizophrenia and other affective disorders (Saha et al. 2016). Chlorpromazine (CPZ) is a typical antipsychotic drug that may have side effects during treatment ( $\mathrm{Li}$ et al. 2008), partially mediated by oxidative stress (Dejanovic et al. 2016).

Oxidative stress (OS) and the products of lipid peroxidation (LPO) are implicated in the pathophysiology of various neurological disorders (Cobb and Cole 2015). Typical antipsychotics have been shown to increase OS by altering the levels of antioxidant enzymes and causing oxidative injury, particularly LPO in the brain (Parikh et al. 2003). Thiobarbituric acid reactive substances (TBARS) are the markers of LPO that significantly increase after CPZ poisoning (Safhi 2016). Nitric oxide (NO) is produced by the action of the isoenzymes of NO synthases (NOS) and it may react with thiol groups in amino acids and proteins to form relatively stable nitroso-thiols (Gergel and Cederbaum 1996).

Biological systems have evolved complex protective strategies against free radical toxicity. These antioxidant defence mechanisms include enzymes that scavenge reactive

Address for correspondence:

Bratislav Dejanovic

Institute of Medical Biochemistry

Military Medical Academy, Belgrade, Serbia
Phone: +381113608404

E-mail: bracadejanovic970@gmail.com

http://actavet.vfu.cz/ 
oxygen and nitrogen species (ROS/RNS), such as catalase (CAT), glutathione peroxidase (GPx), superoxide dismutase (SOD), but also nonenzymatic biomolecules: glutathione (GSH), vitamins $\mathrm{C}$ and $\mathrm{E}$, uric acid (Dringen 2005). The key antioxidant enzyme, SOD, catalyses the conversion of superoxide anion $\left(\mathrm{O}_{2}^{-{ }^{-}}\right)$to hydrogen peroxide $\left(\mathrm{H}_{2} \mathrm{O}_{2}\right)$, which in turn can form the highly reactive hydroxyl radical $(\mathrm{OH} \bullet)$. The other two antioxidant enzymes, CAT and GPx, convert $\mathrm{H}_{2} \mathrm{O}_{2}$ to water (Parikh et al. 2003). Glutathione, a radical scavenger, is converted to oxidized glutathione (GSSG) by the action of GPx and converted back to GSH by the enzyme glutathione reductase (GR).

The present study was aimed to study the potentially beneficial effect of agmatine - AGM (4-aminobutyl) guanidine, on OS development during CPZ toxicity. Agmatine is an amine that is formed by decarboxylation of L-arginine by the enzyme arginine decarboxylase and hydrolysed by the enzyme agmatinase to putrescine (Regunathan et al. 1996). It emerges as neuromodulator and a promising agent to manage diverse central nervous system disorders by modulating the NO pathway, glutamate N-methyl-D-aspartate (NMDA) receptors and OS/nitrosative stress (NS). Also, AGM has recently been shown to have neuroprotective effects due to its antioxidant properties (Chai et al. 2016).

Based on this background, the aim of our study was to investigate the role of ROS/RNS and the efficiency of antioxidant defence in rat selective vulnerable brain regions (VBRs), such as the cerebral cortex, striatum, and hippocampus in subacute CPZ intoxication after AGM treatment.

\section{Materials and Methods}

Animals

Consent of the Ethics Committee for the welfare of experimental animals No. 323-07-03937/2016-05/7 is obtained from Ministry of Agriculture and Environmental Protection - Veterinary Directorate. Adult male Wistar rats (weighing of 200-250 g b.w.) were kept in cages under standardized housing conditions (ambient temperature: $23 \pm 2{ }^{\circ} \mathrm{C}$, relative humidity: $55 \pm 3 \%$ and a light/dark cycle: $13 / 11 \mathrm{~h}$ ) and had free access to standard laboratory pellet food and tap water. The adaptation period to the laboratory conditions was two weeks and all the subsequent procedures were performed between 9:00 $\mathrm{h}$ and 13:00 $\mathrm{h}$.

\section{Experimental procedure}

The experiment was accomplished with the following four experimental groups, which received different testing substances intraperitoneally (i.p.) at the volume of $20 \mu \mathrm{l}$ per $100 \mathrm{~g} \mathrm{~b}$.w. for 15 consecutive days: the control group ( $\mathrm{C}, 0.9 \%$ saline $), \mathrm{n}=10$; the $\mathrm{CPZ}$ group (CPZ-HCl $38.7 \mathrm{mg} / \mathrm{kg}$ b.w.), $\mathrm{n}=10$; the $\mathrm{CPZ}+\mathrm{AGM}$ group (AGM, $75 \mathrm{mg} / \mathrm{kg}$ b.w. i.p., immediately after CPZ-HCl administration, $38.7 \mathrm{mg} / \mathrm{kg}$ b.w.), $\mathrm{n}=10$; and the AGM group (AGM, $75 \mathrm{mg} / \mathrm{kg}$ b.w. i.p.), $\mathrm{n}=10$. The animals were sacrificed by decapitation 15 days after the start of the treatment. The animals' brains were excised and stored at $-20{ }^{\circ} \mathrm{C}$.

\section{Measurement of oxidative/nitrosative status indicators}

The brain structures - cerebral cortex, striatum and hippocampus were dissected on ice, and $0.1 \mathrm{~g}$ of each tissue slice was transferred into sucrose medium $(0.25 \mathrm{M} / 1$ sucrose, $0.1 \mathrm{mM} / 1$ EDTA in $50 \mathrm{mM}$ K-Na phosphate buffer, $\mathrm{pH}$ 7.2). Homogenization was performed on ice by a homogenizer (Tehtnica, Zelezniki, Slovenia) at $800 \mathrm{rotations} / \mathrm{min}$. The homogenates were centrifuged $\left(1000 \times g, 15 \mathrm{~min}, 4^{\circ} \mathrm{C}\right)$, the precipitates were redispersed in sucrose medium, centrifuged $\left(2500 \times \mathrm{g}, 30 \mathrm{~min}, 4^{\circ} \mathrm{C}\right)$ and the obtained precipitates were redispersed in $1.5 \mathrm{ml}$ of deionized water. After that, the samples were centrifuged again $\left(2000 \times \mathrm{g}, 15 \mathrm{~min}, 4^{\circ} \mathrm{C}\right)$ and the supernatants (crude mitochondrial fractions) were stored at $-70{ }^{\circ} \mathrm{C}$ (Gurd et al. 1974). Lipid peroxidation in VBRs was measured as TBARS production as described by Girotti et al. (1991). Data were expressed as nmol per mg of proteins.

After deproteinization the production of $\mathrm{NO}$ was evaluated by measuring nitrite and nitrate concentrations $\left(\mathrm{NO}_{2}\right.$ $+\mathrm{NO}_{3}$ ). Nitrates were previously transformed into nitrites (by cadmium reduction), which were assayed directly spectrophotometrically (Pharmacia Biotech Ultrospec 2000) at $492 \mathrm{~nm}$, using the colorimetric method of Griess (Griess reagent: $1.5 \%$ sulfanilamide in $1 \mathrm{~mol} \mathrm{HCl}$ plus $0.15 \% \mathrm{~N}$-(1-naphthyl)ethylendiamine dihydrochloride in deionized water) (Navarro-Gonzalez et al. 1998). The results were expressed as nmol per mg of proteins.

Superoxide anion radical $\left(\mathrm{O}_{2}{ }^{-}\right)$content was determined through the reduction of nitroblue-tetrazolium (NBT) in the alkaline nitrogen saturated medium. Kinetic analysis was performed at $550 \mathrm{~nm}$ (Auclair and Voisin 1985). The results were expressed as nmol of reduced NBT per min per mg of proteins.

Superoxide dismutase (EC 1.15.1.1.; SOD) activity was measured spectrophotometrically, as an inhibition of epinephrine spontaneous auto-oxidation at $480 \mathrm{~nm}$. The kinetics of sample enzyme activity was followed in

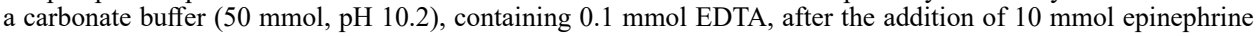


(Sun and Zigman 1978). Data were expressed as microkatal ( $\mu$ kat) per mg of proteins.

Catalase activity (CAT) was determined by the spectrophotometric method. Ammonium molybdate forms a yellow complex with $\mathrm{H}_{2} \mathrm{O}_{2}$ and is suitable for measuring CAT activity in the tissue (Góth 1991). Kinetic analysis was performed at $405 \mathrm{~nm}$. The unit of CAT activity was defined as the number of $\mathrm{H}_{2} \mathrm{O}_{2}$ micromols reduced per $\min \left(\mu \mathrm{mol} \mathrm{H} \mathrm{H}_{2} / \mathrm{min}\right)$. Data were expressed as $\mu$ kat per mg of proteins.

The total glutathione (GSH+1/2GSSG, in GSH equivalents) content was determined using the DTNB-GSSG reductase recycling assay. The rate of formation of 5-thio-2-nitrobenzoic acid (TNB), which is proportional to the total GSH concentration, was followed spectrophotometrically at $412 \mathrm{~nm}$ (Anderson 1986). The results were expressed as nmol per $\mathrm{mg}$ of proteins.

The assessment of GPx activity was determined using a commercial kit (Randox Laboratories Ltd.). GPx catalyses the oxidation of reduced GSH by cumene hydroperoxide. In the presence of reduced GR and nicotinamide adenine dinucleotide phosphate-reduced form (NADPH), the GSSG is immediately converted to the reduced form with a concomitant oxidation of NADPH into $\mathrm{NADP}^{+}$. The decrease in absorbance is measured at $340 \mathrm{~nm}$ (Randox 1996). The unit of enzyme activity of GPx is defined as the number of micromols of NADPH oxidized per min ( $\mu \mathrm{mol} \mathrm{NADPH} / \mathrm{min})$. Data were expressed as $\mu \mathrm{kat}$ per $\mathrm{mg}$ of proteins.

The method for GR activity determination is based on the ability of GR to catalyse the reduction of GSSG to GSH by the oxidation of the coenzyme NADPH into $\mathrm{NADP}^{+}$(Freifelder 1976). In the reaction, we used $100 \mathrm{mmol}$ nicotinamide adenine dinucleotide (NAD) as standard. The unit of enzyme activity is defined as the

A

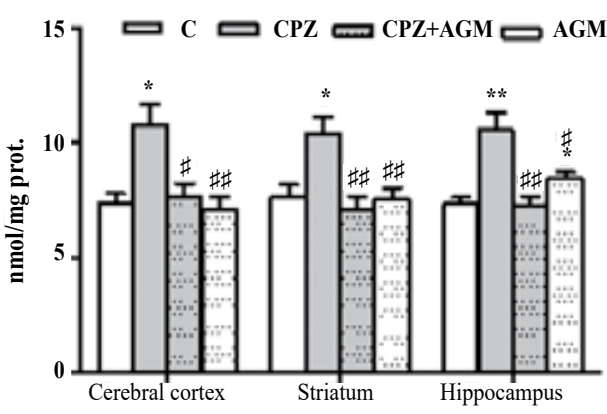

B

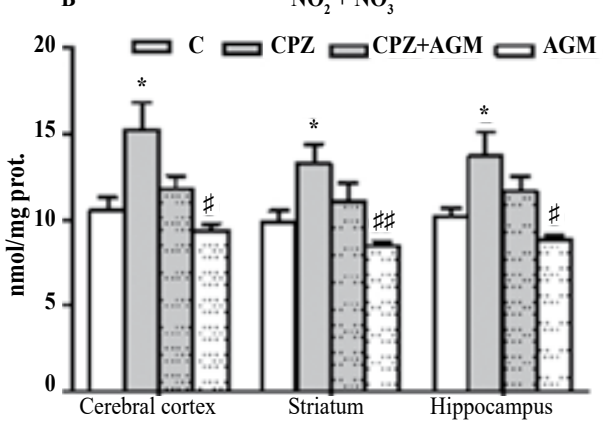

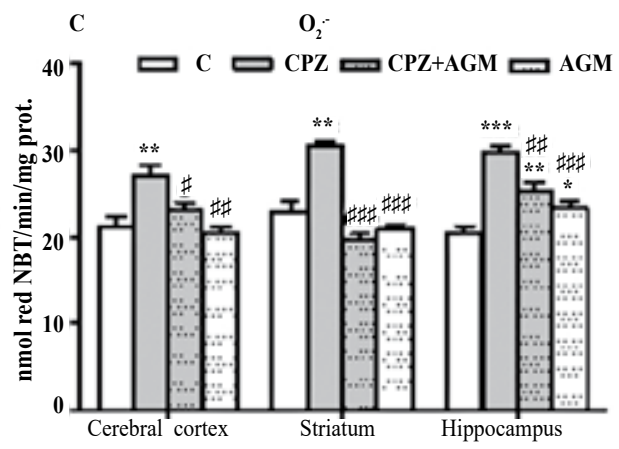

Fig. 1A-C. Oxidative/nitrosative status after appropriate treatment: A) thiobarbituric acid reactive supstances (TBARS; nmol/mg proteins), B) nitrite and nitrate concentrations $\left(\mathrm{NO}_{2}+\mathrm{NO}_{3} ; \mathrm{nmol} / \mathrm{mg}\right.$ proteins) and C) superoxide anion radical $\left(\mathrm{O}_{2}^{-}\right.$, nmol $\mathrm{red} \mathrm{NBT} / \mathrm{min} / / \mathrm{mg}$ proteins) in the rat cerebral cortex, striatum and hippocampus from control (C), chlorpromazine (CPZ), chlorpromazine + agmatine (CPZ+AGM) and agmatine (AGM) groups 15 days after appropriate treatment. Bars in the graph represent mean \pm STDEV from 6 animals of each group. The labels of significance: compared to *control group (C) and \#chlorpromazine-group (CPZ). Statistical significance was considered at $*, \# P<0.05, * *, \# \# P<0.01$ and $* * *$, \#\#\#P<0.001 (One Way ANOVA, Dunnett's test). 
number of micromols of NADPH oxidized per min ( $\mu \mathrm{mol}$ NADPH). The results were expressed as $\mu$ kat per mg of proteins.

The Lowry method was used for protein measurement in rat VBRs (Lowry et al. 1951).

Western blot analysis

After decapitation, the brains from three animals from each group were dissected and pooled. The selected tissue was homogenized with a hand-held pestle in sodium dodecyl sulphate (SDS) sample buffer $(10 \mathrm{ml} / \mathrm{mg}$ ), which contained a cocktail of proteinase and phosphatase inhibitors (Harry et al. 1996). The electrophoresis samples were heated at $100{ }^{\circ} \mathrm{C}$ for $5 \mathrm{~min}$ and loaded onto $10 \%$ SDS-polyacrylamide gels with standard Laemmli solutions (Bio-Rad Laboratories, CA, USA). The proteins were electroblotted onto a polyvinylidene difluoride membrane. The membranes were placed in a blocking solution for $1 \mathrm{~h}$, and incubated overnight under gentle agitation with primary antibody mouse anti-Glial fibrillary acidic protein (GFAP) (1:5000 Abcam, Cambridge,
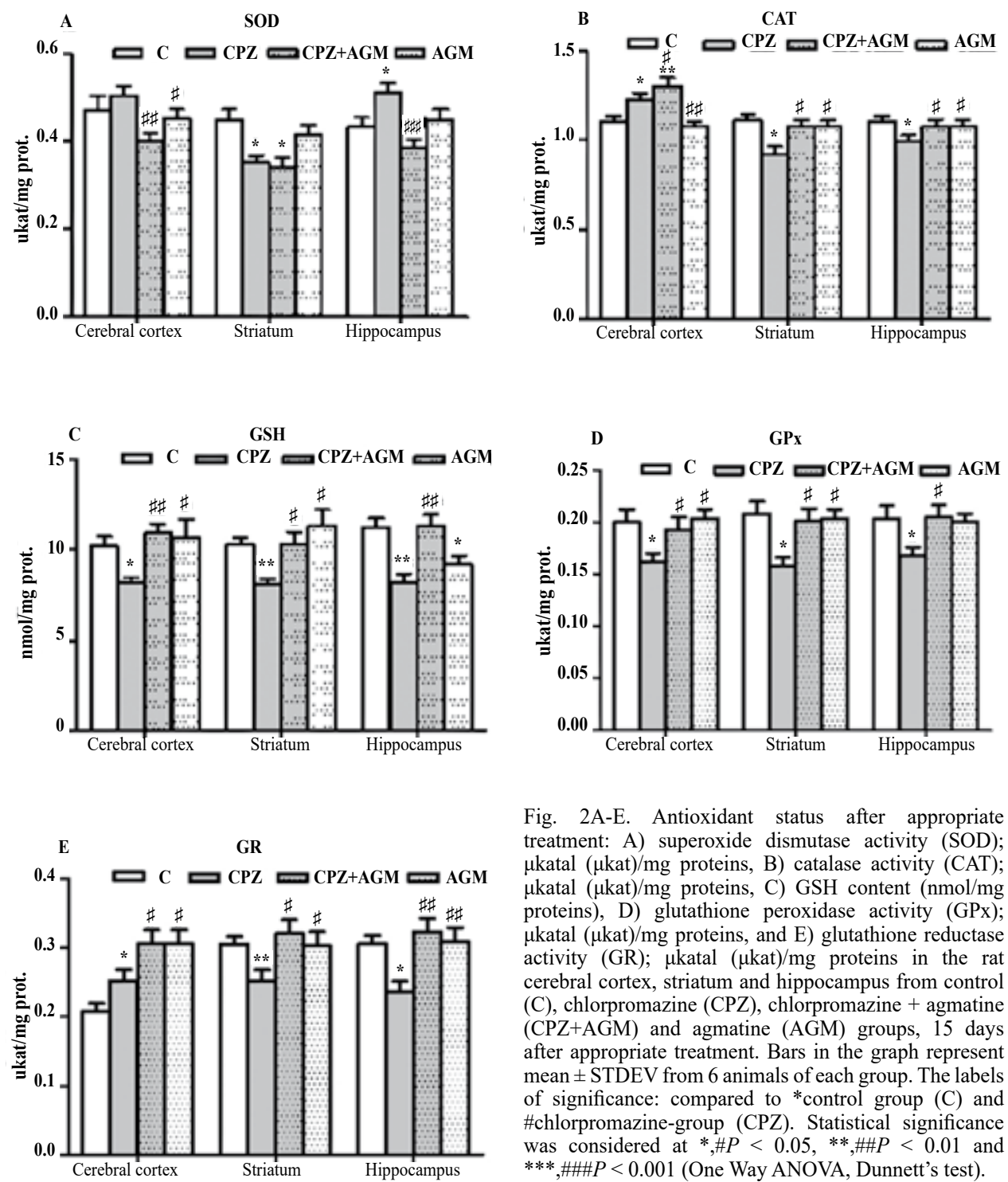

Fig. 2A-E. Antioxidant status after appropriate treatment: A) superoxide dismutase activity (SOD); $\mu \mathrm{katal}(\mu \mathrm{kat}) / \mathrm{mg}$ proteins, B) catalase activity (CAT); $\mu \mathrm{katal}$ ( $\mu \mathrm{kat}) / \mathrm{mg}$ proteins, C) GSH content (nmol/mg proteins), D) glutathione peroxidase activity (GPx); $\mu \mathrm{katal}(\mu \mathrm{kat}) / \mathrm{mg}$ proteins, and E) glutathione reductase activity (GR); $\mu \mathrm{katal}(\mu \mathrm{kat}) / \mathrm{mg}$ proteins in the rat cerebral cortex, striatum and hippocampus from control (C), chlorpromazine (CPZ), chlorpromazine + agmatine $(\mathrm{CPZ}+\mathrm{AGM})$ and agmatine (AGM) groups, 15 days after appropriate treatment. Bars in the graph represent mean \pm STDEV from 6 animals of each group. The labels of significance: compared to * control group (C) and \#chlorpromazine-group (CPZ). Statistical significance was considered at $*, \# P<0.05, * *, \# \# P<0.01$ and ***,\#\#\#P<0.001 (One Way ANOVA, Dunnett's test). 
UK) and mouse anti- $\beta$-actin (1:1000; Sigma, St Louis, MO, USA). Bound primary antibodies were detected with a horseradish peroxidase (HRP)-conjugated anti-mouse secondary antibody (1:5000; Santa Cruz Biotechnology, Santa Cruz, CA, USA). Immunoreactive bands were visualized on X-ray films (Kodak, Rochester, NY, USA), using chemiluminescence. Optical densities of immunoreactive bands from 4 independent blots were calculated in the ImageQuant GE (Healthcare, Chicago, USA). The densities of GFAP and $\beta$-actin immunoreactive bands were quantified with background subtraction. Squares of identical sizes were drawn around each band to measure density, and background near that band was subtracted. For each blot, optical densities were normalized against $\beta$-actin levels.

\section{Statistical analysis}

One-way ANOVA and post hoc Dunnett's C tests were used (software GraphPad Prism, version 5.01, La Jolla, California, USA) for statistical data analysis. Values were presented as means \pm standard deviation (SD). Differences were considered significant at $P<0.05$.

\section{Results}

The CPZ application increased $\mathrm{NO}_{2}+\mathrm{NO}_{3}$ concentration in each brain structure $(P<$ $0.05)$, as well as TBARS concentration $(P<0.05 ; P<0.05 ; P<0.01)$ and $\mathrm{O}_{2}^{--}$production $(P<0.01 ; P<0.01 ; P<0.001)$ in the rat cerebral cortex, striatum and hippocampus, respectively, compared to the $\mathrm{C}$ values. However, $\mathrm{CPZ}+\mathrm{AGM}$ treatment decreased the TBARS concentration $(P<0.05 ; P<0.01 ; P<0.01)$ and $\mathrm{O}_{2}{ }^{*-}$ production $(P<0.01$; $P<0.001 ; P<0.01)$ in the rat cerebral cortex, striatum and hippocampus, respectively, compared to the controls (Fig. 1A-C).

The application of CPZ significantly increased the SOD activity in the hippocampus $(P<0.05)$ and decreased the enzyme activity in the striatum $(P<0.05)$ compared to the controls (Fig. 2A). The CAT activity was significantly increased in the cerebral cortex $(P<0.05)$, and decreased in both the striatum $(P<0.05)$ and the hippocampus $(P<0.05)$ compared to group $\mathrm{C}$ (Fig. $2 \mathrm{~B})$. The $\mathrm{CPZ}$ injection completely decreased and damaged the GPx activity (in each brain structure, $P<0.05)$, as well as the GSH content $(P<$ $0.05 ; P<0.01 ; P<0.01)$ and GR activity $(P<0.05 ; P<0.01 ; P<0.05)$ in the cerebral
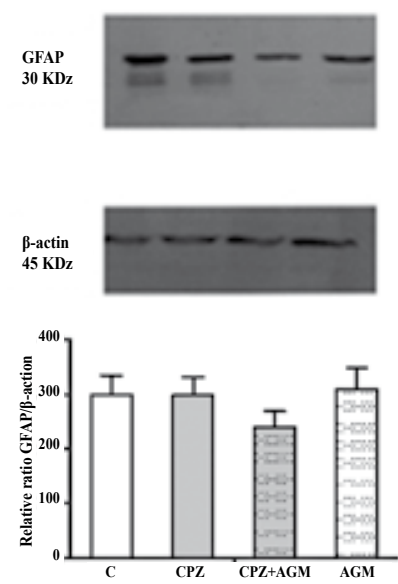
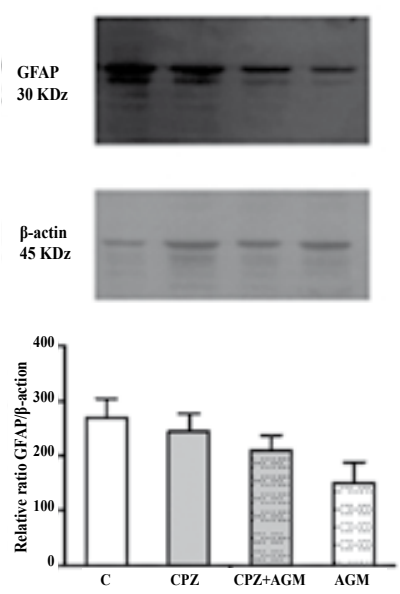
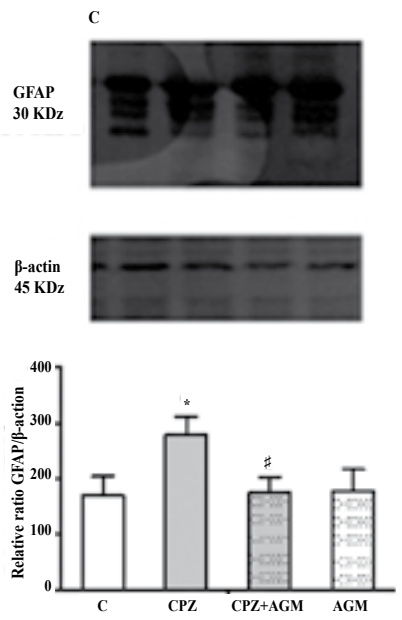

Fig. 3A-C. Quantitative immunoblot detection of glial fibrillary acidic protein (GFAP) protein levels in A) cerebral cortex, B) striatum and C) hippocampus isolated from control (C), chlorpromazine (CPZ), chlorpromazine + agmatine (CPZ+AGM) and agmatine (AGM) groups, 15 days after the treatment. Bars represent mean GFAP protein abundance ( \pm STDEV) from three independent determinations expressed relative to $\beta$-actin. Significance level is shown in the graph $(* P<0.05$ vs. C-group; $\# P<0.05$ vs. CPZ-group), which is accompanied by a representative immunoblot. 
cortex, striatum and hippocampus, respectively, compared to the controls (Fig. 2C-E). The treatment with AGM applied together with CPZ decreased the activity of SOD in the cerebral cortex $(P<0.01)$ and hippocampus $(P<0.001)$ compared to group CPZ (Fig. 2A). However, CPZ + AGM treatment increased both the CAT and GPx activities in each brain structure $(P<0.05)$, as well as the GSH content $(P<0.01 ; P<0.05 ; P<0.01)$ and GR activity $(P<0.05 ; P<0.05 ; P<0.01)$ in the rat cerebral cortex, striatum and hippocampus, respectively, compared to the controls (Fig. 2B-E).

To assess the pattern of GFAP protein expression following CPZ-induced brain injury in rats and after the AGM treatment, the brains were isolated 15 days post injury. Immunoblot analysis showed that GFAP was present in all examined VBRs as a single band with a molecular mass of about $50 \mathrm{kDa}$ (Fig. 3A-C). The CPZ injection increased GFAP expression in the hippocampus compared to the physiological control and decreased its expression in group $\mathrm{CPZ}+\mathrm{AGM}$ in respect to the $\mathrm{CPZ}$-induced injury.

\section{Discussion}

Oxidative stress and LPO with pursuing changes of the antioxidant defence capacity may be responsible for one of the molecular mechanisms of $\mathrm{CPZ}$ intoxication in the brain tissue. Based on our results, we found that AGM has protective effects on the indices of OS/NS in VBRs, and, especially, on the antioxidant defence system.

With regard to the neuroanatomical organization of the brain and selective vulnerability of the examined structures on toxic CPZ effects, there is spatial spreading of damage induced by the drug. It means that biochemical changes were found in the cerebral cortex, striatum, and hippocampus. Our results indicate that $\mathrm{CPZ}$ might disturb the balance between ROS/ RNS production and lead to brain damage through the process comprising the oxidative modification of lipids, which results in a progressive loss of membrane fluidity, reduced membrane potential and increased permeability to ions, such as $\mathrm{Ca}^{2+}(\mathrm{B}$ astianetto et al. 2006). The increase, expressed in percentage of the control was: in the cerebral cortex (TBARS by $48 \%, \mathrm{NO}_{2}+\mathrm{NO}_{3}$ by $50 \%, \mathrm{O}_{2}{ }^{-}$by $28 \%$ ), striatum (TBARS by $38 \%, \mathrm{NO}_{2}+\mathrm{NO}_{3}$ by $34 \%, \mathrm{O}_{2}^{--}$by $33 \%$ ), as well as in the hippocampus (TBARS by $45 \%, \mathrm{NO}_{2}+\mathrm{NO}_{3}$ by $35 \%$, $\mathrm{O}_{2}^{--}$by $45 \%$ ) (Fig. $1 \mathrm{~A}-\mathrm{C}$ ). The significant increase in NO level after CPZ injection (Fig. $1 \mathrm{~B}$ ) indicates that NS may play a significant role in CPZ-induced brain injury (LoresArnaiz et al. 2004). The importance of RNS in CPZ-induced toxicity was demonstrated in different studies which confirmed that low level of NO exerted protective effects on neurons, but high level of $\mathrm{NO}$ could be damaging due to the reaction of $\mathrm{NO}$ with $\mathrm{O}_{2}^{-{ }^{-}}$and the peroxinitrite production (Bosch-Morell et al. 2002; Lores-Arnaiz et al. 2004).

Reactive oxygen species have been shown to be part of both intracellular signalling and intracellular communication, the processes involved in maintaining homeostasis, but when excessively produced in vivo, they are deleterious to integral components of the cell and cause their dysfunctions (Rojczyk et al. 2015). Some experimental data indicate that ROS-mediated LPO, protein oxidation and oxidative alterations to nucleic acids are crucial events of unfavourable actions of ROS (Juranek and Bezek 2005). The increased $\mathrm{O}_{2}{ }^{-}$ production along with decreased GPx activity (Fig. 2D) in all VBRs after CPZ injection suggest damage of the cell antioxidant system.

Also, we previously demonstrated that acute administration of CPZ increased the production of free radicals and affected the antioxidant capacity in the rat brain (Dejanovic et al. 2015, 2016). The results presented here indicate that subacute CPZ application damaged the antioxidant defence system in all examined VBRs (Fig. 2). Striatal spiny neurons serve as a major anatomical locus for the relay of the cortical information flow through the basal ganglia. Subacute administration of CPZ, which resulted in an increase of $\mathrm{O}_{2}{ }^{--}$production and a decrease of SOD activity in the striatum, suggested the presence 
of OS. Also, our study which demonstrated that CPZ induced a decrease in both SOD and CAT activities and an increase in TBARS concentrations in the striatum, was consistent with other studies of CPZ toxicity (Bishnoi et al. 2007). An inadequate free radical sequestration is the consequence of reduced antioxidant enzyme activities. Increased free radical concentrations lead ultimately to oxidative injury of numerous biomolecules, including these enzymes, as well. Reduced CAT activity might be explained by a reduced amount of $\mathrm{H}_{2} \mathrm{O}_{2}$, the substrate of CAT (Djukic et al. 2012). However, the increased SOD activity along with increased TBARS concentration in the hippocampus can be explained by peroxidation in the destruction of membrane lipids.

Glutathione, as a multifunctional, intracellular nonenzymatic antioxidant is the major component of intracellular regulation of the redox state which provides the first line of defence against oxidative injury (Jorgacevic et al. 2013). Also, GSH is an important substrate and cofactor in drug metabolism ( $\mathrm{Nemmiche}$ et al. 2007). Its role in protecting cells from the toxic effects of free radicals and other components with electrophilic properties is reflected in the antioxidant effect, because it neutralizes ROS within cells directly or through the GPx/GSH cycle (Lopert and Patel 2014). Decreased GSH content (Fig. 2C) in inverse proportion to the NO level (Fig. 1B) can be explained by oxidation of GSH within free radical neutralization, as well as its lower synthesis, resulting from decreased production of cysteine as the limiting GSH precursor. It has been previously known that $\mathrm{CPZ}$ is oxidized into $\mathrm{CPZ}$ cation radical, which strongly stimulates oxidation in the presence of $\mathrm{H}_{2} \mathrm{O}_{2}(\mathrm{Hu}$ and Kulkarni 2000). It has been also shown that the different peroxidases and methaemoglobin catalyse single electron oxidation of CPZ into a biologically active CPZ cation radical. This radical is highly reactive and can interact with GSH when CPZ cation radical leads to the formation of glutathione thiol radical cation of CPZ, which is responsible for both pharmacological efficacy and toxic effects of this drug. Since it is known that CPZ affects the formation of free radicals, it would mean that this drug can initiate OS in the brain. Not surprisingly, we found decreased both the GSH content and the GR activity 15 days after CPZ injection (Fig. 2C, E). Other indices confirmed that $\mathrm{OS}$ processes were operative even at subacute $\mathrm{CPZ}$ administration.

It is known that AGM is an endogenous neuromodulator with the potential for new drug development (Piletz et al. 2013). The combined treatment with CPZ and AGM significantly attenuated the OS indices in all examined VBRs (Fig. 1). The beneficial effect of AGM could be related to its ability to inhibit inducible form of NOS or to block NMDA receptors and/or voltage-dependent $\mathrm{Ca}^{2+}$ channels (Reis et al. 1998). Blockade of either of these signalling proteins would likely be protective. A possible explanation for the unchanged NO level and the decreased TBARS concentration might be that NO acts as a ROS scavenger, protects cells from LPO and consequently prevents progressive increase of the TBARS level. These results indicate that LPO might have a more important role in protection after AGM administration in CPZ toxicity than NS. Also, the reduced $\mathrm{O}_{2}^{--}$production confirms the protective effect of AGM and can be explained by its total antioxidant potential.

Additionally, the CPZ+AGM treatment which caused the significant decrease in the TBARS concentration, suggested the activation of the antioxidant system, resulting in an aggressive oxidative mechanism blockade initiated by $\mathrm{CPZ}$ application. Our study demonstrated the massive increase of enzymatic (CAT, GPx) and nonenzymatic (GSH) antioxidant capacity, showing adequate antioxidant cell defence against neuronal injuries (Fig. 2).

The neuroprotective roles of AGM were confirmed by the improvement of the OS status development indicators (decreased TBARS and increased GSH concentration). Also, the increased GR activity in the $\mathrm{CPZ}+\mathrm{AGM}$ group indicated the importance of maintaining the content of GSH at the level necessary to achieve the antioxidant role (Fig. 2E). In fact, the increased GR activity sustained GSH levels by extracellular reduction of GSSG. 
Based on the electrophoretic profiles of the GFAP molecules, an indicator of reactive astroglial changes to neuronal damage in VBRs, we found clear differences in the levels of expression of the protein, which were most pronounced in the hippocampus after subacute CPZ treatment (Fig. 3C). Decreased GFAP expression 15 days after the CPZ+AGM treatment could indicate reduced astrogliosis in the hippocampus with a region-specific decrease in GFAP expressing cell profiles.

In conclusion, our data revealed that ROS/RNS were included in CPZ-induced neurotoxicity, resulting in both temporal and spatial spreading of damage to the VBRs, so that AGM could have potentially neuroprotective effect and partially ameliorated oxidative/nitrosative damage after CPZ toxicity. Explanation of damage mechanisms after CPZ-induced neurotoxicity can be of great importance for both veterinary and human medicine in preventing altered functional and structural conditions in the brain tissue. The use of AGM can improve health and physical capability as well as lead to better recovery after poisoning.

\section{Acknowledgements}

This work was supported by the Military Medical Academy, Projects No. MФВМА/1/18-20, as well as by the Ministry of Education, Science and Technological Development of the Republic of Serbia, Project No. III41014. No conflict of interest exists for any of the authors of this article.

\section{References}

Anderson ME 1986: The DTNB-GSSG reductase recycling assay for total glutathione (GSH + 1/2GSSG). In: Greenwald RA (Ed.): Tissue glutathione. Boca Raton, CRC Press, pp 317-323

Auclair C, Voisin E 1985: Nitroblue tetrazolium reduction. In: Greenwald RA (Ed.): Handbook of Methods for Oxygen Radical Research. CRC Press, Florida, pp 123-132

Bastianetto S, Danik M, Mennicken F, Williams S, Quirion R 2006: Prototypical antipsychotic drugs protect hippocampal neuronal cultures against cell death induced by growth medium deprivation. BMC Neurosci 7: 28

Bishnoi M, Chopra K, Kulkarni SK 2007: Possible anti-oxidant and neuroprotective mechanisms of zolpidem in attenuating typical anti-psychotic-induced orofacial dyskinesia: a biochemical and neurochemical study. Prog Neuropsychopharmacol Biol Psychiatry 31: 1130-1138

Bosch-Morell F, Romá J, Marín N, Romero B, Rodriguez-Galietero A, Johnsen-Soriano S, Díaz-Llopis M, Romero FJ 2002: Role of oxygen and nitrogen species in experimental uveitis: anti-inflammatory activity of the synthetic antioxidant ebselen. Free Radic Biol Med 33: 669-75

Chai J, Luo L, Hou F, Fan X, Yu J, Ma W, Tang W, Yang X, Zhu J, Kang W, Yan J, Liang H 2016: Agmatine reduces lipopolysaccharide-mediated oxidant response via activating PI3K/Akt pathway and up-regulating Nrf2 and HO-1 expression in macrophages. PLoS One 11: e0163634

Cobb CA, Cole MP 2015: Oxidative and nitrative stress in neurodegeneration. Neurobiol Dis 84: 4-21

Dejanovic B, Ninkovic M, Stojanovic I, Lavrnja I, Radicevic T, Stevanovic I 2015: Agmatine prevents acute chlorpromazine-induced neurotoxicity in rats. Arh farm 65: 287-303

Dejanovic B, Stevanovic I, Ninkovic M, Stojanovic I, Lavrnja I, Radicevic T, Pavlovic M 2016: Agmatine protection against chlorpromazine-induced forebrain cortex injury in rats. J Vet Sci 17: 53-61

Djukic M, Jovanovic MD, Ninkovic M, Stevanovic I, Curcic M, Topic A, Vujanovic D, Djurdjevic D 2012: Intrastriatal pre-treatment with L-NAME protects rats from diquat neurotoxicity. Ann Agric Environ Med 19: $666-672$

Dringen R 2005: Oxidative and antioxidative potential of brain microglial cells. Antioxid Redox Signal 7: 1223-1233

Freifelder D 1976: Physical Biochemistry. Application to Biochemistry and Molecular Biology. Freeman WH and $\mathrm{Co}$, San Francisco

Gergel D, Cederbaum AI 1996: Inhibition of the catalytic activity of alcohol dehydrogenase by nitric oxide is associated with S nitrosylation and the release of zinc. Biochemistry 35: 16186-16194

Girotti M, Khan N, Lellan B 1991: Early measurement of systemic lipid peroxidation products in the plasma of major blunt trauma patients. J Trauma 31: 32-35

Góth L 1991: A simple method for determination of serum catalase activity and revision of reference range. Clin Chim Acta 196: 143-151

Gurd JW, Jones LR, Mahler HR, Moore WJ 1974: Isolation and partial characterization of rat brain synaptic membrane. J Neurochem 22: 281-290

Harry GJ, Schmitt TJ, Gong Z, Brown H, Zawia N, Evans HL 1996: Lead-induced alterations of glial fibrillary acidic protein (GFAP) in the developing rat brain. Toxicol Appl Pharmacol 139: 84-93 
Hu J, Kulkarni AP 2000: Metabolic fate of chemical mixtures. I. "Shuttle Oxidant" effect of lipoxygenasegenerated radical of chlorpromazine and related phenothiazines on the oxidation of benzidine and other xenobiotics. Teratog Carcinog Mutagen 20: 195-208

Jorgacevic B, Mladenovic D, Ninkovic M, Prokic V, Stankovic M, Aleksic V, Cerovic I, Vukicevic RJ, Vucevic D, Stankovic M, Radosavljevic T 2013: Dynamics of oxidative/nitrosative stress in mice with methioninecholine-deficient diet-induced nonalcoholic fatty liver disease. Hum Exp Toxicol 33: 701-709

Juránek I, Bezek S 2005: Controversy of free radical hypothesis: reactive oxygen species-cause or consequence of tissue injury? Gen Physiol Biophys 24: 263-278

Li T, Zhou Q, Zhang N, Luo Y 2008: Toxic effects of chlorpromazine on Carassius auratus and its oxidative stress. J Environ Sci Health B 43: 638-643

Lopert P, Patel M 2014: Brain mitochondria from DJ-1 knockout mice show increased respiration-dependent hydrogen peroxide consumption. Redox Biol 2: 667-672

Lores-Arnaiz S, D’Amico G, Czerniczyniec A, Bustamante J, Boveris A 2004: Brain mitochondrial nitric oxide synthase: in vitro and in vivo inhibition by chlorpromazine. Arch Biochem Biophys 430: 170-177

Lowry OH, Rosenbrongh NJ, Farr AL, Randal RJ 1951: Protein measurement with the folin phenol reagent. J Biol Chem 193: 265-275

Navarro-Gonzalez JA, Garcia-Benayas C, Arenas J 1998: Semiautomated measurement of nitrate in biological fluids. Clin Chem 44: 679-681

Nemmiche S, Chabane-Sari D, Guiraud P 2007: Role of alpha-tocopherol in cadmium-induced oxidative stress in Wistar rat's blood, liver and brain. Chem Biol Interact 170: 221-230

Parikh V, Khan MM, Mahadik SP 2003: Differential effects of antipsychotics on expression of antioxidant enzymes and membrane lipid peroxidation in rat brain. J Psychiatr Res 37: 43-51

Piletz JE, Aricioglu F, Cheng JT, Fairbanks CA, Gilad VH, Haenisch B, Halaris A, Hong S, Lee JE, Li J, Liu P, Molderings GJ, Rodrigues AL, Satriano J, Seong GJ, Wilcox G, Wu N, Gilad GM 2013: Agmatine: clinical applications after 100 years in translation. Drug Discov Today 18: 880-893

Randox Laboratories 1996: Ltd. Radicales Libres, Crumlin, United Kingdom, pp 1-16

Regunathan S, Youngson C, Raasch W, Wang H, Reis DJ 1996: Imidazoline receptors and agmatine in blood vessels: a novel system inhibiting vascular smooth muscle proliferation. J Pharmacol Exp Ther 276: 1272-1282

Reis DJ, Yang XC, Milner TA 1998: Agmatine containing axon terminals in rat hippocampus form synapses on pyramidal cells. Neurosci Lett 250: 185-188

Rojczyk E, Pałasz A, Wiaderkiewicz R 2015: Effect of short and long-term treatment with antipsychotics on orexigenic/anorexigenic neuropeptides expression in the rat hypothalamus. Neuropeptides 51: $31-42$

Safhi MM 2016: Neuromodulatory effects of thymoquinone in extenuating oxidative stress in chlorpromazine treated rats. Acta Pol Pharm 73: 529-535

Saha KB, Bo L, Zhao S, Xia J, Sampson S, Zaman RU 2016: Chlorpromazine versus atypical antipsychotic drugs for schizophrenia. Cochrane Database Syst Rev 2016; 4: CD010631

Sun M, Zigman S 1978: An important spectrophotometric assay for superoxide dismutase based on epinephrine auto-oxidation. Analytical Biochemistry 90: 81-89 